\title{
ANALISIS KUALITAS SUMBER DAYA INSANI PADA LEMBAGA KEUANGAN MIKRO SYARIAH
}

\section{ANALYSIS OF QUALITY OF HUMAN RESOURCES IN ISLAMIC MICRO FINANCIAL INTITUTIONS}

\author{
R. Windasari'1a; M. Paramita² \\ 1aProgram Studi Perbankan Syariah Fakultas Ekonomi Islam Universitas Djuanda, Jl. Tol \\ Ciawi No. 1, Kotak Pos 35 Bogor 16720, e-mail: riantiwindasari15@gmail.com \\ 2Program Studi Perbankan Syariah Fakultas Ekonomi Islam Universitas Djuanda, Jl. Tol \\ Ciawi No. 1, Kotak Pos 35 Bogor 16720
}

\begin{abstract}
This study aims to determine the quality and work performance of human resource development in five Islamic micro financial institutions in Bogor City. The method used is descriptive qualitative. Primary data in this research are observation and depth interview. Based on the result of the research, it is concluded that in several Islamic micro financial institutions has the quality of human resources is good, and has implemented development system for human resources so that there is improvement in terms of skill, knowledge and good attitudes, the statement is reinforced by employee performance indicators, the work of each employee and some support programs of training and development undertaken by all employees owned by each LKMS.
\end{abstract}

Keywords : Quality of Human Resources, BMT, KSPPS

\begin{abstract}
ABSTRAK
Penelitian ini bertujuan untuk mengetahui kualitas dan kinerja kerja sumber daya insani pada lima lembaga keuangan mikro syariah di Kota Bogor. Metode penelitian menggunakan deskriptif kualitatif. Data primer pada penelitian ini yaitu observasi dan wawancara mendalam. Berdasarkan hasil penelitian, disimpulkan bahwa beberapa LKMS memiliki kualitas SDI yang baik, dan telah melakukan sistem pengembangan untuk SDI, agar terdapat peningkatan dari segi keterampilan, pengetahuan dan sikap yang baik, pernyataan tersebut diperkuat dengan indikator kinerja karyawan, hasil kerja setiap karyawan dan beberapa program pendukung yaitu kegiatan pelatihan serta pengembangan karyawan yang dimiliki setiap LKMS.
\end{abstract}

Kata Kunci: Kualitas Sumber Daya Insani, BMT, KSPPS

Windasari, Rianti. 2018. Analisis Kualitas Sumber Daya Insani Pada Lembaga Keuangan Mikro Syariah. Jurnal Syarikah 4 (2): 83-98. 


\section{PENDAHULUAN}

Perkembangan industri keuangan pada lembaga keuangan mikro syariah (LKMS) saat ini tidak diimbangi oleh sumber daya insani (SDI) yang memadai, hal ini dapat menimbulkan dampak pada operasional LKMS. Selain itu, karyawan yang memiliki pengalaman pada bidang perbankan syariah, maupun instansi keuangan lain masih sangat minim. Kualitas SDI pada LKMS seperti BMT memiliki produktifitas serta mampu memajukan pembangunan perekonomiannya. Perekonomian nasional dapat dibangun dengan sumber daya manusia yang berkualitas dan memiliki pengetahuan, keterampilan serta berpendidikan (Stamboel, 2012).

LKMS harus mempersiapkan kualitas SDI yang kompeten, karena kualitas SDI dapat menentukan pengembangan lembaga keuangan dimasa mendatang. Untuk dapat menggerakkan bisnis syariah, tentu memerlukan SDI yang memahami ilmu bisnis syariah secara baik. Kenyataannya selama ini, beberapa karyawan pada instansi keuangan lain dengan lulusan sarjana umum yang diberikan training singkat mengenai keuangan syariah. Training seperti ini tidak memadai untuk menciptakan SDI yang benar-benar handal dan kompeten pada bidang perbankan (Isa, 2016:25).

Terkait dengan masalah Sumber Daya Insani, UI mengungkapkan lebih dari 90\%, SDI pada instansi keuangan syariah serta LKMS, sebagian SDI tidak memiliki background pendidikan ekonomi syariah. Jumlah SDI pada LKMS didominasi oleh karyawan yang tidak mengetahui pengetahuan tentang keuangan Islam. LKMS merupakan lembaga keuangan mikro yang melibatkan SDI dan memiliki kualifikasi, kualitas serta kompetensi tidak hanya ahli di bidang ekonomi dan perbankan, namun mereka harus memiliki kualifikasi, kualitas dan kompetensi syariah (Nasichin, 2010:113).

SDI atau karyawan pada suatu perusahaan/lembaga perlu dikendalikan dengan baik, sehingga berperan optimal dan memberikan kontribusi baik bagi perkembangan perusahaan/lembaga serta menjadi penentu kesuksesan lembaga keuangan dalam menjalankan usahanya. Pertumbuhan LKMS tentunya harus seimbang dengan ketersediaan kualitas SDI (Mangkuprawira, 2011:133).

Sebagai sistem LKMS yang relatif lembaga keuangan baru, hal wajar jika LKMS dilingkupi banyak permasalahan yang memperlambat pengembangan LKMS dimasa depan. Persoalan yang terjadi diantaranya, regulasi yang tidak lengkap, keterbatasan cakupan pasar, rendahnya tingkat pemahaman masyarakat terhadap produk LKMS, institusi pendukung yang kurang efektif, kualitas mengenai SDI, serta manajemen yang kurang efektif dalam meningkatkan bisnis keuangan mikro syariah. Salah satu sumber daya paling utama pada LKMS yaitu sumber daya manusia yang memiliki tenaga, keahlian, kreatifitas, dan usaha karyawan demi kemajuan suatu organisasi, maka sebuah LKMS dapat berkembang secara optimal dan kualitas SDI pada LKMS merupakan sumber kekuatan bagi suatu organisasi (Harmoyo, 2012:302).

\section{MATERI DAN METODE}

\section{Sumber Daya Insani}

Manajemen SDI merupakan bidang manajemen umum, yang melingkupi suatu perencanaan, pengorganisasian, 
pelaksanaan serta pengendalian. Perbaikan utama peran SDI sebagai pelaksana dari fungsi lembaga keuangan yaitu perencanaan, pengorganisasian, karyawan, kepemimpinan, pengendalian dan pengawasan serta pelaksana operasional perusahaan. Pada dasarnya tujuan yang dicapai manajemen SDI adalah peningkatan efisiensi, efektifitas, dan produktifitas, minimnya tingkat perpindahan karyawan, tingkat kehadiran karyawan/absensi dan complain dari nasabah, tingginya tingkat kualitas pelayanan, dan meningkatnya bisnis perusahaan (Rivai, 2009:23).

Manajemen SDI adalah suatu perencanaan yang mengorganisir suatu tujuan secara sustainable melalui potensi yang dimiliki karyawan untuk sebuah pencapaian dan keseimbangan suatu tujuan, baik bersifat materi maupun bersifat abstrak/immaterial. Ada beberapa tujuan terkait penerapan manajemen SDI pada LKMS yaitu:

1. Peningkatan efisiensi, efektifitas, dan produktifitas.

2. Rendahnya tingkat peralihan karyawan, tingkat kehadiran/absensi karyawan dan complain dari nasabah.

3. Meningkatnya kinerja karyawan dan kualitas pelayanan.

4. Meningkatnya bisnis perusahaan.

Dengan adanya tujuan yang dicapai melalui proses manajemen SDI, maka proses pencapaian suatu organisasi lebih cepat serta efisien (Rivai, 2009:23).

Manajemen SDI merupakan manajemen yang penting, karena berkaitan dengan performa instansi keuangan syariah atau perusahaan dalam menghasilkan suatu produk dan jasa. SDI menjadi indikator utama dalam perusahaan sehingga diperlukan untuk diperhatikan secara individu karyawan maupun secara kelompok. LKMS membutuhkan SDI yang tidak hanya menguasai masalah operasional dan manajerial, akan tetapi mengetahui tentang fiqih ekonomi Islam atau fiqh al-muamalah bersumber pada nilai-nilai Islam. Dalam sebuah etika, sifat shiddiq dan amanah menjadi landasan pada setiap karyawan, hal ini tercermin pada integritas muslim yang berkualitas. SDI pada LKMS harus skillfull professional (fathanah) dan mampu melaksanakan tugas dengan team work, serta dapat memberi informasi di seluruh fungsional organisasi (tabligh). Begitupun mengenai reward dan punishment diperlukan sebagai prinsip keadilan sesuai dengan aturan syariah (Ali, 2010:48).

Tugas dan fungsi utama dari manajemen SDI adalah memilih karyawan yang memiliki kualitas serta spesifikasi tinggi, sehingga suatu hal yang mengenai perencanaan,

pengorganisasian, pengarahan, dan pengkontrolan pada perusahaan dapat direncanakan dengan optimal. Terdapat beberapa ketentuan yang harus dimiliki oleh SDI pada lembaga keuangan syariah diantaranya:

1. Kemampuan dalam menarik nasabah serta memahami hubungan antara lembaga dan nasabah.

2. Kemampuan memberikan pelayanan dengan maksimal dan berkualitas.

3. Kemampuan mengetahui peluang investasi, dan dapat mempelajari, mengevaluasi, mengimplementasikan dan melakukan pengawasan.

Melalui manajemen SDI yang professional dapat meningkatkan kualitas manajemen secara keseluruhan, sehingga dapat menambah performa LKMS (Wadoed, 2011:68).

\section{Kualitas SDI}

SDI merupakan sumber kompetitif paling utama pada perusahaan. Salah satu pengelolaan utama dalam perusahaan yaitu 
pengelolaan SDI. Kualitas SDI adalah kemampuan dalam berfikir, berkomunikasi, bertindak dalam melakukan suatu kegiatan, baik bersifat teknis maupun manajerial. Manusia memiliki taraf mulia yang memiliki akal pikiran dan perasaan. SDI yang berkualitas merupakan manusia yang mengembangkan pengetahuannya berdasarkan akal yang dimiliki, karena setiap insan mempunyai potensi-potensi yang harus dikembangkan. Kualitas SDI tidak cukup dengan memiliki pengetahuan dan ilmu teknologi, tetapi sesuai dengan pengembangan kualitas nilai-nilai syariah dan spiritual yaitu berupa iman dan takwa. Ketahanan kualitas SDI tidak sempurna tanpa ada ketangguhan mental spiritual keagamaan (Komang, 2012:302).

Mengenai kualitas SDI terdapat dua aspek diantaranya aspek kuantitas dan kualitas. Kuantitas SDI berkaitan dengan jumlah SDM yang tidak berkontribusi dalam pembangunan. Kuantitas SDM tidak menyangkut mengenai kualitas yang optimal dan dapat menjadi beban pembangunan. Sedangkan, kualitas menyangkut dengan mutu SDI tersebut. Hal ini untuk kepentingan percepatan suatu pembangunan pada lembaga keuangan syariah, maka meningkatnya kualitas SDI merupakan suatu persyaratan utama (Soekidjo, 2011:5).

Kualitas SDI pada LKMS diantaranya yaitu:

\section{Kualitas Fisik}

Kualitas SDI mencakup dua aspek yaitu kualitas fisik, dan kualitas non fisik. Kedua aspek ini mengenai kemampuan bekerja, berfikir dan keterampilanketerampilan lain. Dengan hal ini upaya pengembangan kualitas SDI ini harus sesuai pada kedua aspek fisik dan non fisik. Pencapaian kualitas fisik diupayakan dengan program kesehatan jasmani serta meningkatkan kualitas non fisik dalam upaya program pendidikan merupakan yang paling diperlukan. Salah satu upaya ini disebut sebagai pengembangan SDI (Notoatmodjo, 2010:4).

2. Kualitas Non Fisik

Indikator kualitas non fisik diantaranya yaitu pengetahuan, keterampilan, memiliki kemampuan pendidikan, memiliki tingkat kualitas pendidikan serta keterampilan yang relevan dengan memperhatikan lingkungan kerja serta memiliki pengetahuan dibidang ilmu teknologi sesuai dengan tuntutan pekerjaan. Kualitas non fisik diantaranya yaitu keterampilan, pengetahuan, sikap dan agama.

\section{Lembaga Keuangan Mikro Syariah}

LKMS merupakan lembaga keuangan dengan melakukan kegiatan mengumpulkan dana masyarakat dan menyalurkan kembali pada masyarakat dengan menggunakan prinsip syariah. LKMS memberikan fasilitas pinjaman/kredit dengan lalu lintas pembayaran sesuai prinsip-prinsip syariah. Dengan asumsi perbandingan lembaga keuangan salah satunya yaitu bank yang memiliki modal berskala besar, maka lembaga keuangan mikro merupakan kata bentuk lain dari bank yang memiliki capital kecil dan khusus untuk sektor usaha mikro (Sudarsono, 2010:96).

LKMS terdiri dari beberapa lembaga diantaranya BMT dan koperasi syariah. BMT merupakan lembaga keuangan yang beroperasi menggunakan prinsip bagi hasil, dan menjalankan usaha mikro serta bertujuan merubah derajat serta martabat kaum fakir miskin, dengan berlandaskan sistem ekonomi yang sallam yaitu keselamatan, kedamaian dan kesejahteraan (Al Arif, 2012: 317). Didirikannya BMT 
memiliki tujuan salah satunya upaya dalam menambah kualitas usaha demi kesejahteraan anggota dan masyarakat. Anggota harus diberdayakan atau empowering, agar dapat mandiri (Ridwan, 2010:128).

Tugas umum BMT salah satunya yaitu melaksanakan pembinaan masyarakat dan melakukan pendanaan sesuai prinsip syariah, diantaranya yaitu:

1. Mengidentifikasi, mengorganisasi, dan meningkatkan potensi ekonomi anggota.

2. Menambah kualitas SDI yang profesional dan Islami.

3. Menggerakkan potensi masyarakat dengan tujuan meningkatkan kesejahteraan anggota.

4. Menjadi intermediasi keuangan antara aghniya sebagai shahibul maal dengan kaum dhuafa sebagai mudharib, terutama dana sosial. Salah satu fungsi BMT diantaranya sebagai amil penerima dana zakat, infaq, shadaqah, dan dana sosial untuk disalurkan kembali pada golongan-golongan yang membutuhkan.

5. Menjadi peranan antara pemilik dana, sebagai pemodal dan penyimpan sebagai pengguna dana.

Koperasi syariah merupakan badan koperasi yang melakukan kegiatan usaha sesuai prinsip syariah. Koperasi syariah memiliki usaha simpan pinjam. Semua produk dan cara operasionalnya dilakukan mengacu pada fatwa DSN MUI. Berdasarkan ketentuan tersebut, koperasi syariah dilarang melakukan kegiatan yang mengandung unsur riba, maysir dan gharar. Koperasi syariah juga tidak diperkenankan melakukan beberapa transaksi derivatif yang dilakukan lembaga keuangan lain (Limbong, 2010:65).
Salah satu tujuan koperasi syariah yaitu dapat memajukan kesejahteraan anggota dan masyarakat serta membangun perekonomian negara Indonesia berdasarkan prinsip-prinsip Islam. Terdapat fungsi koperasi syariah diantaranya:

1. Membangun dan menumbuhkan potensi, kemampuan anggota khususnya masyarakat, dalam memajukan kesejahteraan sosial ekonomi.

2. Memperkuat kualitas nasabah dengan amanah, profesional (fathonah), konsisten, dan konsekuen (istiqomah) dalam menerapkan prinsip syariah.

3. Berusaha mewujudkan pengembangan perekonomian nasional atas dasar asas kekeluargaan dan asas demokrasi ekonomi.

4. Mengembangkan dan memperluas kesempatan kerja (Bernhard Limbong, 2010:67-68).

\section{Metodologi Penelitian}

Jenis penelitian yang digunakan yaitu deskriptif kualitatif. Jenis penelitian ini memberikan gambaran/penjabaran atau uraian beserta pemaparan suatu keadaan/situasi secara jelas tanpa respon khusus pada obyek yang diteliti. Metode yang digunakan pada penelitian ini yaitu descriptif analysis. Sumber data dalam penelitian terdiri dari data primer dan data sekunder yang diperoleh melalui wawancara, observasi dan dokumentasi yang dilakukan pada beberapa LKMS sebagai tempat penelitian. (Sugiyono, 2010: 5-17).

Data primer pada penelitian adalah SOP (Standar Operasional Prosedur), dokumen laporan pertanggungjawaban pengurus tahun buku 2016 dan dokumen rencana kerja\&anggaran tahun 2016, dokumen aspek keanggotaan LKMS, data 
aspek kualitas Sumber Daya Manusia (SDM) dan data dari hasil wawancara, data observasi yang diberikan manajemen LKMS, Struktur Organisasi LKMS. Sedangkan data sekunder diperoleh dari internet, undang-undang, buku, jurnal, skripsi, tesis dan literatur lainnya (Sugiyono, 2015: 225).

Teknik pengumpulan data yang dilakukan yaitu wawancara dengan pihak manajemen khususnya kepala cabang LKMS yang memahami tentang kualitas SDI, selanjutnya adalah observasi non partisipan yaitu kegiatan pengumpulan data melalui pengamatan atas gejala, fenomena dan fakta empiris mengenai masalah penelitian, serta tidak terlibat langsung melainkan hanya mengamati proses kinerja SDI pada LKMS, serta dokumentasinya pada penelitian dan terakhir teknik kepustakaan yaitu referensi dari buku-buku, artikel dan sumber lainnya (Sugiyono, 2013:197, Musfiqon, 2012: 120, Sugiyono, 2013: 326).

Populasi penelitian adalah LKMS wilayah Bogor diantaranya BMT dan Koperasi Syariah. Sampling diambil secara purposive sampling, dimaksudkan agar sampel memberikan informasi dalam menyusun model peningkatan kualitas SDI pada LKMS melalui kualitas fisik dan kualitas non fisik. Pada tempat penelitian diambil 5 LKMS yaitu BMT Berkah Mandiri Sejahtera, KSPPS Berkah Bersama, KSPPS BMT Binaul Ummah, KBMT Tabiirul Ummah, dan Koperasi Baytul Ikhtiar (BAIK). Keseluruhan sampel berjumlah 5 (lima) LKMS.

Teknis analisis data yang digunakan yaitu model Spradley dengan empat tahap analisis yaitu analisis domain, analisis taksonomi, analisis komponensial dan analisis tema kultural. Penelitian dilakukan berdasarkan masalah bagaimana pihak manajemen pada LKMS mengatasi persoalan tentang kualitas SDI dan bagaimana upaya dalam meningkatkan kualitas SDI tersebut. Maka subyek yang dipilih yaitu bagian sumber daya insani/karyawan dan objek penelitian ini yaitu LKMS.

\section{HASIL DAN PEMBAHASAN}

\section{Gambaran Lembaga Keuangan Mikro Syariah di Bogor}

1. BMT Berkah Mandiri Sejahtera

Mengacu pada regulasi pemerintah tahun 2016, bahwa semua KJKS harus diganti dengan KSPPS. Maka dengan ketentuan tersebut "BMT Berkah Mandiri Sejahtera" harus berubah nama yang tadinya KJKS dirubah menjadi KSPPS. Seiring dengan perkembangan zaman pada awal tahun 2015 "KSPPS BMT" Berkah Mandiri Sejahtera sudah membuka kantor Unit Layanan di daerah Cariu Jonggol Kabupaten Bogor bertujuan untuk memperluas pelayanan kepada masyarakat. Perkembangan dan pertumbuhan KSPPS tersebut beberapa tahun kedepan terus meningkat karena memiliki dukungan dan kepercayaan dari beberapa pihak, diantaranya dukungan dan kepercayaan anggota, dari Bank Syariah Mandiri, Bank Muamalat Indonesia, Diskoperindag (Pemerintah), dan LKM lainnya serta dukungan beberapa organisasi seperti, Dekopinda, Puskopsyah dan Absindo.

Berdasarkan dengan UU Koperasi Nomor 25 Tahun 1992 dan peraturan pemerintah bahwa setiap bentuk koperasi harus memiliki badan hukum, maka bulan Juli tahun 2013 "KSPPS BERKAH MANDIRI SEJAHTERA" yang beralamat di Jl. Raya Puncak Cisarua Ruko Blok C.II No. 11 A Desa Citeko Kecamatan Cisarua Kabupaten 
Bogor, resmi memiliki badan hukum dengan Nomor Badan Hukum:518/314/BH/KTPS/DISKOPERIND AG/VII/2013, dan Surat Keputusan Kementrian Negara Koperasi dan UKM Republik Indonesia. KSPPS BMT Berkah Mandiri Sejahtera memiliki kegiatan ekonomi kerakyatan dengan falsafah "Dari anggota, oleh anggota, dan untuk anggota" serta memiliki motto "Manfaat dan maslahat untuk Ummat".

2. KSPPS Berkah Bersama

Koperasi Simpan Pinjam dan Pembiayaan Syariah (KSPPS) Berkah Bersama merupakan sebuah lembaga pada bidang jasa keuangan dan berbadan hukum. Koperasi didirikan pada februari 2013 di Kota Bogor. Namun, cikal bakal sebelum diterbitkannya badan hukum berdiri di tahun 2012. KSPPS Berkah Bersama ini awalnya bernama KJKS Berkah Bersama diganti menjadi KSPPS Berkah Bersama sesuai dengan peraturan dari menteri Koperasi. Awal berdiri KSPPS Berkah Bersama terdiri dari dua belas (12) Founder yang memiliki tujuan, visi dan misi yaitu membentuk satu lembaga keuangan syariah yang profesional dan dapat menyentuh kalangan usaha kecil dan menengah. Dengan modal awal Rp. 50.000.000-, KSPPS melangsungkan usahanya yang bertempat di Jl. Meyjen Ishak Djuarsa No. 6 Kelurahan Loji Kota Bogor dengan jumlah karyawan 5 orang. KSPPS Berkah Bersama memiliki dua kantor layanan yaitu di Caringin dan Leuwisadeng Kabupaten Bogor. Setelah tiga tahun berselang, Berkah Bersama membentuk tiga kantor layanan di Serang, Cibinong, dan Gunung Batu. Kemudian membuka sebuah kantor layanan baru di Parung. Jadi, total kantor layanan cabang Berkah Bersama berjumlah enam (6) dengan kantor pusat Berkah Bersama saat ini berada di Jalan Baru Yasmin Kabupaten Bogor.

3. KSPPS BMT Binaul Ummah

KSPPS BMT Binaul Ummah selama ini berkiprah dalam upaya memberdayakan ekonomi kecil dengan menerapkan sistem ekonomi syariah. Dalam perjalanannya keberadaan BMT Binaul Ummah besar sekali manfaat yang bisa dirasakan oleh masyarakat, terutama pengusaha kecil di wilayah kota dan kabupaten bogor. Tahun 2016 merupakan tahun kerja yang tidak berbeda dari tahun sebelumnya, dimana prestasi kerja BMT BUM belum menunjukkan peningkatan yang signifikan dari sisi finansial, yang dilakukan saat ini dalam upaya bagaimana upaya LKMS tetap eksis dalam pemberdayaan ekonomi masyarakat, ditengah banyaknya lembagalembaga pesaing yang memiliki beberapa pengalaman dan lebih profesional dalam menjalankan bisnis sektor micro finance ini. Disamping itu di tahun 2016 banyak sekali tantangan yang dihadapi, salah satu tantangan yaitu sulitnya mengakses dana perbankan dalam upaya menambah modal kerja KSPPS BMT BUM. Padahal perbankan biasanya menjadi alternatif sumber pendanaan bagi KSPPS BMT BUM, namun tahun 2016 untuk mengakses dana ke perbankan begitu sulit mereka memberlakukan beberapa persyaratan yang tidak mungkin KSPPS BMT BUM bisa memenuhinya. Tidak seperti pada tahuntahun sebelumnya persyaratan yang diminta cukup mudah untuk dipenuhi. Namun demikian KSPPS BMT Binaul Ummah selama tahun 2016 masih tetap bisa mempertahankan eksistensinya, padahal dilain pihak terdapat beberapa instansi keuangan lain yang mengalami persoalan dalam mempertahankan eksistensi lembaganya, dan banyak yang mengalami collapse bahkan sampai 
bangkrut. Akan tetapi, saat ini BMT masih tetap bisa melayani kebutuhan anggotanya. Dengan hal ini, KSPPS Binaul Ummah memperoleh dukungan dan do'a dari semua pihak yang tetap bekerjasama dengan KSPPS BMT Binaul Ummah. Meskipun selama tahun 2016 KSPPS BMT Binaul Ummah belum mengalami peningkatan prestasi yang signifikan dari sisi kinerjanya, akan tetapi ada hal lain yang membanggakan KSPPS BMT, dimana pada tahun ini pengurus KSPPS dapat mewujudkan harapan yaitu memiliki gedung kantor operasional milik sendiri yang cukup representatif. Hal ini cukup memberikan dorongan, ketenangan dan kenyamanan semua karyawan BMT Binaul Ummah dalam bekerja. Pada Tahun 2016 KSPPS BMT Binaul Ummah ditetapkan sebagai koperasi berprestasi tingkat Kota Bogor dengan SK Walikota Nomor 518.45149 tahun 2016.

4. KBMT Tabiirul Ummah

KBMT Tadbiirul Ummah didirikan sebagai Lembaga Pemberdayaan Masyarakat di daerah Bogor. Perkembangan KBMT dibina oleh yayasan PERAMU (Pemberdayaan Mustadhaffin) sebagai inisiator pada tanggal 20 Desember 1995. Pada tahun 1998, Tadbiirul Ummah memiliki izin operasi sebagai Koperasi dengan No. Badan Hukum: 05/BH/KDK.105/VIII/1998 dengan jumlah anggota 20 orang. Pada tahun 2015, Peraturan Menteri semua koperasi yang menjalankan kegiatan simpan, pinjam dan pembiayaan dengan prinsip syariah dirubah menjadi KSPPS. Total anggota/mitra layanan (pembiayaan dan penyimpan dana aktif) kurang lebih 3.500 orang. KBMT Tadbiirul Ummah melayani 7 kecamatan di Kabupaten dan Kota Bogor, diantaranya Dramaga, Ciampea, Tenjolaya, Ciomas, Babakan Madang, Sukaraja,
Cibinong, dan Kota Bogor, Pasar Ciluar dan beberapa wilayah perdagangan disekitar Kampus IPB Dramaga.

5. Koperasi Baytul Ikhtiar (BAIK)

$$
\text { Koperasi Baytul Ikhtiar (BAIK) }
$$

merupakan koperasi yang bekerjasama dengan Yayasan Pengembangan Masyarakat Mustadh'affin (PERAMU). Tahun 2008 Koperasi Baitul Ikhtiar resmi menjadi koperasi berbadan hukum. Baitul Ikhtiar memulai kegiatan kerja dengan melaksanakan program pemberdayaan masyarakat miskin melalui Unit Pelayanan Keuangan (UPK) Ikhtiar. Program tersebut dimulai pada tahun 1991 di wilayah pedesaan Kecamatan Tamansari dan berkembang dikawasan miskin perkotaan Bogor pada tahun 2002. Tahun 2003, pelayanan UPK Ikhtiar digunakan sebagai proses pembentukan kelompok pedagang sayuran di pasar jambu dan kota Bogor dengan tujuan membangun kapasitas sosial ekonomi keluarga berpenghasilan rendah agar memiliki kemampuan dalam memenuhi kebutuhan dasar melalui pengelolaan asset ekonomi rumah tangga.

\section{Kualitas SDI pada LKMS di Bogor}

Secara umum, kualitas SDI pada masing-masing LKMS di Kota Bogor terdapat dua faktor yaitu kualitas fisik yang terdiri dari sehat jasmani dan kualitas non fisik yang terdiri dari keterampilan, pengetahuan, sikap dan agama SDI. Keadaan sehat jasmani karyawan pada LKMS diperlukan sebagai fasilitas pendukung, karena keadaan sehat jasmani secara fisik dapat menghasilkan kinerja kerja dengan optimal. Kondisi fisik sehat jasmani menjadi perhatian khusus oleh LKMS, karena dengan memiliki kondisi fisik yang sehat maka SDI yang dimiliki dapat melakukan pekerjaannya dengan maksimal. 
Upaya yang dilakukan LKMS dalam meningkatkan kualitas dan kompetensi SDI pada umumnya tidak hanya fokus pada kualitas fisik akan tetapi, dengan kualitas non fisik. Dengan keterampilan dan pengetahuan SDI merupakan jalan utama untuk dapat menghasilkan SDI yang berkualitas serta memiliki pengaruh signifikan dalam peningkatan kompetensi SDI pada LKMS. Lembaga Keuangan Mikro Syariah memerlukan peningkatan pengetahuan serta keterampilan yang dimiliki masing-masing SDI yaitu dengan mengikuti kegiatan pendidikan dan pelatihan. Pendidikan dan pelatihan menjadi faktor utama dalam upaya meningkatkan kualitas SDI pada LKMS.

SDI menjadi faktor utama bagi LKMS, karena SDI sebagai penggerak dan pelaku dalam menjalankan sebuah usaha pada lembaga keuangan. LKMS berupaya dengan semaksimal mungkin dalam mengelola lembaga keuangan dengan memiliki SDI berkualitas dan mampu melaksanakan penugasan ekonomi syariah. Maju mundurnya usaha LKMS tergantung pada kemampuan SDI, untuk itu diperlukan suatu program dalam upaya peningkatan kualitas SDI yaitu rekruitmen dan pembinaan karir, reward dan punishment pada karyawan.

\section{Kualitas SDI di BMT Berkah Mandiri Sejahtera}

Untuk meningkatkan potensi kualitas para karyawan, BMT Berkah Mandiri Sejahtera memberikan beberapa kegiatan pelatihan. Kegiatan pelatihan dan pendidikan yang dilakukan diantaranya untuk memenuhi kebutuhan operasional BMT Berkah Mandiri Sejahtera.

BMT Berkah Mandiri Sejahtera melakukan kerjasama dalam pelatihan SDI yaitu dengan lembaga Diklat Profesi PINBUK, Lembaga Absindo, Lembaga LSP
Perkoperasian Indonesia, Balai Pelatihan Koperasi dan Usaha Mikro Kecil Provinsi Jawa Barat, Dinas Koperasi UKM Perindustrian dan Perdagangan, DEKOPINDA. Karyawan dididik untuk memiliki sehat jasmani maupun rohani serta memiliki keterampilan, pengetahuan, perilaku yang baik dengan tujuan membangun keahlian dan kemampuan dari semua karyawan.

Kualitas fisik SDI menjadi modal utama dan salah satu fasilitas pendukung bagi BMT Berkah Mandiri Sejahtera, hal ini menjadi faktor penting, karena sehat jasmani secara fisik dapat menghasilkan kinerja dengan maksimal. Kesehatan memiliki dampak positif pada produktifitas karyawan. Dengan hal ini, kepala cabang BMT Berkah Mandiri Sejahtera memberikan pengetahuan tentang sehat jasmani secara langsung dan tidak langsung tentang pentingnya kesehatan pada SDI serta memberikan arahan mengenai pola hidup sehat dengan tujuan dapat meningkatkan retensi karyawan dan mengurangi daftar ketidakhadiran serta menghemat biaya perawatan kesehatan BMT Berkah Mandiri Sejahtera. Kepala cabang BMT menjamin kesehatan SDI yaitu dengan mengatur jam kerja dan menciptakan kinerja para karyawan secara optimal. Tingkat kehadiran karyawan pada KSPPS Berkah Mandiri Sejahtera cukup berkualitas, karena kesehatan karyawan cukup terjamin dan setiap karyawan memiliki Kartu BPJS.

Adapun laporan Daftar Karyawan yang memiliki Kartu BPJS yaitu: 
Tabel 1

Daftar Karyawan yang memiliki kartu BPJS

\begin{tabular}{|l|l|l|l|}
\hline No & Nama & Jabatan & Ket \\
\hline 1. & Winda Safitri & Teller & Memiliki \\
\hline 2. & Ira & Teller & Memiliki \\
\hline 3. & $\begin{array}{l}\text { Tommy } \\
\text { Nugraha }\end{array}$ & Marketing & Memiliki \\
\hline 4. & $\begin{array}{l}\text { Cecep } \\
\text { Bustomi }\end{array}$ & Marketing & Memiliki \\
\hline
\end{tabular}

Sumber: Data BMT Berkah Mandiri

Sejahtera, 2016

Semua karyawan memiliki jaminan kesehatan, akan tetapi tidak langsung dibiayai oleh BMT Berkah Mandiri Sejahtera, karena terkait dengan Kartu BPJS tidak syariah. Adapun karyawan yang sakit dan tidak harus dirawat inap pihak KSPPS Berkah Bersama mengcover semua biaya pengobatan karyawan.

Adapun laporan kegiatan pelatihan SDI di BMT Berkah Mandiri Sejahtera pada tahun 2015-2016 yaitu:

Tabel 2

Laporan Realisasi kegiatan pelatihan

Sumber Daya Insani pada BMT Berkah Mandiri Sejahtera

\begin{tabular}{|c|c|c|c|c|}
\hline $\begin{array}{l}\mathrm{N} \\
\mathrm{O}\end{array}$ & $\begin{array}{l}\text { Jenis } \\
\text { Pendidika } \\
\text { n \& \& } \\
\text { Pelatihan }\end{array}$ & $\begin{array}{l}\text { Penyelen } \\
\text { ggara } \\
\text { Diklat }\end{array}$ & $\begin{array}{l}\text { Waktu } \\
\text { Pelaksa } \\
\text { naan }\end{array}$ & $\begin{array}{l}\text { Jumlah } \\
\text { Peserta } \\
\text { yang } \\
\text { disertak } \\
\text { an }\end{array}$ \\
\hline 1 & $\begin{array}{l}\text { Sistem } \\
\text { Akuntans } \\
\text { i } \\
\text { Terintegr } \\
\text { asi }\end{array}$ & $\begin{array}{l}\text { Dinas } \\
\text { Koperasi } \\
\text {, UKM, } \\
\text { Perindus } \\
\text { trian dan } \\
\text { Perdaga } \\
\text { ngan } \\
\end{array}$ & $\begin{array}{l}\text { Novem } \\
\text { ber, } \\
2014\end{array}$ & $\begin{array}{l}\text { Manajer } \\
\text { dan } \\
\text { Bagian } \\
\text { Adm }\end{array}$ \\
\hline 2 & $\begin{array}{l}\text { Fundame } \\
\text { ntal } \\
\text { Spritual\& } \\
\text { Motivatio } \\
n\end{array}$ & $\begin{array}{l}\text { LPM } \\
\text { Universi } \\
\text { tas } \\
\text { Tazkia } \\
\text { dan } \\
\text { Takaful }\end{array}$ & $\begin{array}{l}\text { Februa } \\
\text { ri, } \\
2015\end{array}$ & $\begin{array}{l}\text { Manajer } \\
\& A O\end{array}$ \\
\hline 3 & $\begin{array}{l}\text { BIMTEK } \\
\text { ADMINIS } \\
\text { TRASI } \\
\text { ORGANIS } \\
\text { ASI } \\
\end{array}$ & $\begin{array}{l}\text { Dinas } \\
\text { Koperasi } \\
\text { UKM, } \\
\text { Perindus } \\
\text { trian dan }\end{array}$ & $\begin{array}{l}\text { Maret, } \\
2015\end{array}$ & $\begin{array}{l}\text { Manajer } \\
\text { dan } \\
\text { Bagian } \\
\text { Adm }\end{array}$ \\
\hline
\end{tabular}

\begin{tabular}{|l|l|l|l|l|}
\hline & $\begin{array}{l}\text { KOPERAS } \\
\text { I }\end{array}$ & $\begin{array}{l}\text { Perdaga } \\
\text { ngan }\end{array}$ & & \\
\hline 4 & $\begin{array}{l}\text { Sertifikasi } \\
\text { Kompete } \\
\text { nsi } \\
\text { Manajer }\end{array}$ & $\begin{array}{l}\text { Dinas } \\
\text { Koperasi } \\
\text { UnM, } \\
\text { Perindus } \\
\text { trian dan } \\
\text { Perdaga } \\
\text { ngan }\end{array}$ & $\begin{array}{l}\text { Mei, } \\
2015\end{array}$ & $\begin{array}{l}\text { Ketua } \\
\text { Penguru } \\
\text { s dan } \\
\text { Manajer }\end{array}$ \\
\hline 5 & $\begin{array}{l}\text { Pengelola } \\
\text { LKMS }\end{array}$ & $\begin{array}{l}\text { LPM } \\
\text { Universi } \\
\text { tas } \\
\text { Tazkia }\end{array}$ & $\begin{array}{l}\text { Novem } \\
\text { ber, } \\
2015\end{array}$ & $\begin{array}{l}\text { Manajer } \\
\text { dan AO }\end{array}$ \\
\hline 6 & $\begin{array}{l}\text { Study } \\
\text { Banding } \\
\text { ke } \\
\text { KOPKAR } \\
\text { Subang }\end{array}$ & $\begin{array}{l}\text { PUSKOP } \\
\text { SYAH } \\
\text { dan } \\
\text { Dinas } \\
\text { Koperasi }\end{array}$ & $\begin{array}{l}\text { Februa } \\
\text { ri, } \\
2016\end{array}$ & $\begin{array}{l}\text { Manajer } \\
\text { dan AO }\end{array}$ \\
\hline
\end{tabular}

Sumber: Data BMT Berkah Mandiri Sejahtera, 2016

Semua realisasi kegiatan pelatihan membuktikan bahwa semua SDI mengikuti pelatihan yang bertujuan meningkatkan keterampilan serta pengetahuan karyawan. SDI KSPPS Berkah Mandiri Sejahtera memiliki integritas, etika serta moralitas yang mewajibkan setiap karyawan menjalankan pekerjaannya untuk besikap jujur dan konsisten. Integritas pada KSPPS Berkah Mandiri Sejahtera memastikan semua proses dan perilaku kerja berjalan dengan sepenuh hati, totalitas, jujur, dan bertanggung jawab. Sikap dalam bekerja karyawan pada KSPPS Berkah Mandiri Sejahtera yaitu selalu menempatkan kegiatan kerja sebagai ibadah, karyawan selalu menghentikan semua pekerjaan pada waktu shalat, karyawan selalu memberi pelayanan dengan baik (excellent service), dan bersikap ramah pada setiap anggota. Pimpinan KSPPS Berkah Mandiri Sejahtera selalu mengarahkan semua SDI untuk memotivasi ibadah mencapai ridha Allah SWT, karena motivasi ibadah dalam etos kerja Islam sangat penting dalam melaksanakan kegiatan kerja. Oleh karena itu, semua SDI pada KSPPS Berkah Mandiri 
Sejahtera wajib memiliki motivasi kerja Islam dengan baik. Sumber Daya Insani juga menerapkan sifat-sifat Rasulullah, sifat amanah wajib dimiliki oleh semua karyawan, karena pada hakikatnya segala perbuatan manusia, tidak satu pun lepas dari sebuah pertanggungjawaban termasuk aktifitas kerja pada lembaga keuangan. Sifat shidiq pada karyawan KSPPS Berkah Mandiri Sejahtera tentu harus dimiliki.

\section{Kualitas SDI di KSPPS Berkah Bersama}

KSPPS Berkah Bersama Cabang Caringin memiliki program pelatihan dengan tujuan untuk mengembangkan keterampilan serta menambah pengetahuan diantaranya program hari mutu. Kegiatan hari mutu adalah kegiatan seperti briefing, kegiatan ini memberikan materi kepada semua SDI Cabang Caringin. Materi yang diberikan yaitu mengenai ekonomi Islam, perbankan syariah dan ilmu ekonomi. Pembinaan semua karyawan dilakukan setiap minggunya, pembinaan dilakukan untuk menambah wawasan karyawan.

Kualitas fisik SDI menjadi perhatian khusus oleh pihak manajemen, karena dengan kondisi kesehatan yang prima, karyawan dapat melakukan tugas kerjanya dengan maksimal. Adapun daftar karyawan yang memiliki Kartu BPJS pada tahun 2017 di KSPPS Berkah Bersama cabang Caringin yaitu:

\section{Tabel 3}

Daftar Karyawan yang memiliki kartu BPJS dan KIS

\begin{tabular}{|l|l|l|l|}
\hline No & \multicolumn{1}{|c|}{ Nama } & Jabatan & \multicolumn{1}{c|}{ BPJS/KIS } \\
\hline 1 & Apip & FA & Memiliki \\
\hline 2 & Amin & FA & Memiliki \\
\hline 3 & Supriyatna & FA & Memiliki \\
\hline 4 & Firman & FA & Memiliki \\
\hline 5 & Syamsu & AO & Memiliki \\
\hline 6 & Lisda & Adm & Memiliki \\
\hline 7 & Fitri & Teller & Memiliki \\
\hline
\end{tabular}

Sumber: Data KSPPS Berkah Bersama, 2017

Semua karyawan KSPPS Berkah Bersama mendapatkan jaminan kesehatan yaitu program kesehatan dari pemerintah kartu BPJS dan Kartu KIS. Pada KSPPS Berkah Bersama terdapat beberapa pelatihan SDI dalam meningkatkan serta menambah pengetahuan serta keahlian karyawan. Karyawan baru maupun karyawan lama wajib ikut serta dalam melaksanakan pelatihan yang diselenggarakan KSPPS Berkah Bersama. Bagi karyawan baru wajib mengikuti on the job training, yaitu pelatihan mengenai penugasan karyawan-karyawan yang telah berpengalaman untuk membimbing dan mengajarkan kepada karyawan baru. Pelatihan on the job training yang dilakukan yaitu selama tiga bulan. Adapun daftar latar belakang pendidikan dari masing-masing karyawan diantaranya:

Tabel 4

Daftar Latar belakang pendidikan SDI pada KSPPS Berkah Bersama

\begin{tabular}{|l|l|l|l|}
\hline No & \multicolumn{1}{|c|}{ Nama } & \multicolumn{1}{|c|}{ Jabatan } & \multicolumn{1}{|c|}{ Lulusan } \\
\hline 1 & Aris & Manager & S1 Djuanda \\
\hline 2 & Apip & FA & $\begin{array}{l}\text { S1 Inais } \\
\text { Sahid }\end{array}$ \\
\hline 3 & Amin & FA & $\begin{array}{l}\text { SI Inais } \\
\text { Sahid }\end{array}$ \\
\hline 4 & Supriyatna & FA & MA \\
\hline 5 & Firman & FA & SMK Inais \\
\hline 6 & Syamsu & AO & $\begin{array}{l}\text { S1 Sahid } \\
\text { Sanais }\end{array}$ \\
\hline 7 & Lisda & ADM & $\begin{array}{l}\text { S1 In } \\
\text { Sahid }\end{array}$ \\
\hline 8 & Fitri & Teller & $\begin{array}{l}\text { D3 } \\
\text { Politeknik }\end{array}$ \\
\hline
\end{tabular}

Sumber: Data KSPPS Berkah Bersama, 2017

Dari background pendidikan masingmasing karyawan ternyata terdapat beberapa background pendidikan terakhir S1 dan sebagian lulusan tingkat SMA. 
Dengan latar belakang pendidikan dari masing-masing SDI, tentu hal ini berpengaruh dengan tingkat pengetahuan karyawan. Maka pelatihan SDI pada sebuah lembaga keuangan berkaitan dengan hasil kinerja dari masing-masing karyawan. Pelatihan yang diselenggarakan pada KSPPS Berkah Bersama diantaranya pelatihan keterampilan yaitu pelatihan teller dan pelatihan accounting, dan pelatihan motivasi. Pihak manajemen KSPPS Berkah Bersama memberikan arahan mengenai etika moralitas serta integritas kepada semua SDI. Adapun sikap, etika, perilaku yang harus dimiliki karyawan diantaranya yaitu profesionalisme, open minded, jujur, team work, rendah hati, dan sikap kritis.

\section{Kualitas SDI di BMT Binaul Ummah}

Upaya yang dilakukan dalam menambah serta meningkatkan kualitas SDI pada Binaul Ummah salah satunnya yaitu memberikan berbagai pelatihan kepada SDI diantaranya pelatihan internal dan pelatihan eksternal. Pelatihan internal yang dilakukan yaitu pelatihan kerja yang dilakukan setiap hari serta memberikan arahan-arahan tentang keterampilan dan keahlian oleh pihak manajemen. Pelatihan internal yang dilakukan bersifat tidak resmi, pelatihan internal merupakan salah satu pelatihan yang seharusnya diselenggarakan. Adapun pelatihan eksternal pada BMT Binaul Ummah bersifat resmi dan diprogramkan serta diadakan oleh pemerintah dan lembaga-lembaga swasta lain. BMT Binaul Ummah melakukan kerjasama mengenai pelatihan dengan lembaga lain diantaranya Lembaga Diklat Profesi PINBUK, Dinas Koperasi dan Pemerintah. Adapun laporan kegiatan pelatihan yang diikuti oleh karyawan pada tahun 2016, yaitu:
Tabel 5

Laporan Realisasi kegiatan pelatihan karyawan BMT Binaul Ummah

\begin{tabular}{|l|l|l|l|l|}
\hline $\begin{array}{l}\text { N } \\
\text { o }\end{array}$ & $\begin{array}{l}\text { Nama } \\
\text { Kegiatan } \\
\text { Pelatihan }\end{array}$ & $\begin{array}{l}\text { Penyeleng } \\
\text { gara } \\
\text { Pelatihan }\end{array}$ & $\begin{array}{l}\text { Waktu } \\
\text { Pelaksan } \\
\text { aan } \\
\text { Pelatiha } \\
\text { n }\end{array}$ & $\begin{array}{l}\text { Pes } \\
\text { erta }\end{array}$ \\
\hline 1 & $\begin{array}{l}\text { Teknik } \\
\text { Internal } \\
\text { Audit }\end{array}$ & $\begin{array}{l}\text { ABSINDO } \\
\text { Sukabumi }\end{array}$ & $\begin{array}{l}\text { Februari, } \\
2016\end{array}$ & $\begin{array}{l}\text { Zuh } \\
\text { rotu } \\
\text { l }\end{array}$ \\
\hline 2 & $\begin{array}{l}\text { Studi } \\
\text { Banding } \\
\text { ke } \\
\text { KOPKAR }\end{array}$ & $\begin{array}{l}\text { PUSKOPSY } \\
\text { AH, Dinas } \\
\text { Koperasi }\end{array}$ & $\begin{array}{l}\text { Februari, } \\
\text { 2016 }\end{array}$ & $\begin{array}{l}\text { Agu } \\
\text { s }\end{array}$ \\
\hline 3 & $\begin{array}{l}\text { Pelatihan } \\
\text { Tax } \\
\text { Amnesty } \\
\text { dan pajak }\end{array}$ & $\begin{array}{l}\text { Dekopinda } \\
\text { Kota } \\
\text { Bogor }\end{array}$ & $\begin{array}{l}\text { Septemb } \\
\text { er, 2016 }\end{array}$ & $\begin{array}{l}\text { Zuh } \\
\text { rotu } \\
\text { lan }\end{array}$ \\
\hline 4 & $\begin{array}{l}\text { Pelatihan } \\
\text { Pengawas } \\
\text { Koperasi }\end{array}$ & $\begin{array}{l}\text { Kementria } \\
\text { n KUMKM } \\
\text { RI\&DSN }\end{array}$ & $\begin{array}{l}\text { Septemb } \\
\text { er, 2016 }\end{array}$ & $\begin{array}{l}\text { Agu } \\
\text { s }\end{array}$ \\
\hline
\end{tabular}

Sumber: Data BMT Binaul Ummah, 2016

Dari realisasi kegiatan pelatihan yang diikuti karyawan, membuktikan bahwa semua SDI mengikuti pelatihan bertujuan untuk menambah keterampilan serta pengetahuan karyawan, meningkatkan kuantitas serta kualitas produktifitas kerja, membentuk sikap, dan menambah loyalitas karyawan dalam pengembangan pribadi.

Kualitas SDI dipengaruhi dengan lingkungan kerja, pelatihan motivasi kerja, etos kerja dan keadaan fisik karyawan. Pendidikan serta pelatihan menjadi upaya untuk memperoleh dan menambah pengetahuan serta keterampilan bagi masing-masing karyawan. Pada dasarnya tingkat pendidikan karyawan berkaitan dengan pengembangan intelektual, serta dapat menambah aspek pengetahuan yang dimiliki setiap. Tidak hanya mengikutsertakan pelatihan SDI, BMT Binaul Ummah mengadakan kegiatan pengajian rutin dengan tujuan melandasi setiap aktifitas kerja karyawan yang semata-mata hanya karena Allah SWT. BMT 
Binaul Ummah mendukung perilaku yang agamis dengan mewajibkan karyawannya untuk mendirikan shalat berjamaah ketika sudah masuk waktu shalat, dan menjunjung tinggi akhlaqul karimah karyawannya dalam melakukan kegiatan apapun dalam kesehariannya. Semua karyawan menerapkan prinsip sifat Rasulullah SAW yaitu sifat siddiq, amanah, fathonah, tabligh dalam aktifitas kerjanya.

\section{Kualitas SDI KBMT Tadbiirul Ummah}

Kualitas fisik merupakan asset yang diperlukan oleh KBMT Tadbiirul Ummah, karena secara fisik keadaan sehat jasmani karyawan dapat memberikan kinerja kerja dengan optimal dan menunjang kinerja kerja terhadap produktifitas. Dengan meningkatnya kualitas fisik SDI tentu sangat berpengaruh terhadap tingkat absensi karyawan di Tadbiirul Ummah. Tingkat absensi karyawan cukup baik dan konsisten, salah satunya KBMT memiliki program yang dilakukan untuk menjaga kesehatan kerja karyawan. Adapun jenis program kesehatan pada karyawan diantaranya:

1) Kesehatan fisik

Dalam jaminan kesehatan secara fisik yaitu kesehatan jasmani, kepala cabang KBMT mendaftarkan semua SDI kepada asuransi JAMSOSTEK.

2) Kesehatan Mental

Pemberian layanan kesehatan mental pada Tadbiirul Ummah belum bekerja sama dengan pihak psikiater dari luar dalam hal kesehatan mental. KBMT Tadbiirul Ummah baru memberikan dalam hal pencerahan melalui penyejukan keimanan seperti mengadakan kajian Al-Quran serta kajian tentang agama yang dilakukan setiap jum'at pagi.

Adapun faktor utama pada Tadbiirul Ummah yaitu keterampilan, pengetahuan yang dimiliki karyawan untuk menjalankan sebuah usaha lembaga keuangan. KBMT Tadbiirul Ummah melakukan sistem pengembangan dengan upaya untuk menambah peningkatan kualitas SDI diantaranya:

1) Rekrutmen

2) Pembinaan karir, reward, dan punishment karyawan.

Pelatihan yang diadakan diantaranya yaitu pelatihan keterampilan dan pelatihan motivasi. Pelatihan keterampilan mengenai pengenalan dan pemahaman keterampilan bersifat (hard skill) maupun pengembangan pribadi (soft skill). Pelatihan yang dilakukan bertujuan untuk menambah pengetahuan maupun skill karyawan. Salah satu pelatihan keterampilan adalah:

1) Pelatihan Teller

2) Pelatihan Accounting

3) Pelatihan Team Marketing

4) Pelatihan Manajemen

Terdapat program pelatihan bertujuan mengembangkan keterampilan semua karyawan Tadbiirul Ummah diantaranya program yang dilakukan setiap hari sabtu yaitu in house training.

Adapun laporan kegiatan pelatihan karyawan tahun 2016 diantaranya:

Tabel 6

Laporan Realisasi kegiatan pelatihan SDI

\begin{tabular}{|c|c|c|c|c|}
\hline $\begin{array}{l}\mathrm{N} \\
\mathrm{O}\end{array}$ & $\begin{array}{c}\text { Nama } \\
\text { Kegiatan }\end{array}$ & $\begin{array}{c}\text { Pelaksan } \\
\text { a/PJ }\end{array}$ & $\begin{array}{c}\text { Waktu } \\
\text { Pelaksana } \\
\text { an }\end{array}$ & $\begin{array}{l}\text { Partisi } \\
\text { pan }\end{array}$ \\
\hline 1 & $\begin{array}{l}\text { Seminar } \\
\text { Takaful } \\
\text { Asuransi } \\
\text { Umum }\end{array}$ & $\begin{array}{l}\text { Asuransi } \\
\text { Takaful }\end{array}$ & $\begin{array}{l}3 \\
\text { Februari, } \\
2016\end{array}$ & $\begin{array}{l}\text { SA, } \\
\text { HRD, } \\
\text { NL dan } \\
\text { FS }\end{array}$ \\
\hline 2 & $\begin{array}{l}\text { Pelatiha } \\
\mathrm{n} \text { Audit } \\
\text { Internal }\end{array}$ & $\begin{array}{l}\text { Asosiasi } \\
\text { BMT Se } \\
\text { Indonesi } \\
\text { a }\end{array}$ & $\begin{array}{l}\text { 4-5 } \\
\text { Februari, } \\
2016\end{array}$ & $\mathrm{NL}$ \\
\hline 3 & $\begin{array}{l}\text { Pelatiha } \\
\mathrm{n} \\
\text { Anggota } \\
\text { tentang } \\
\text { pencatat }\end{array}$ & $\begin{array}{l}\text { Mien R } \\
\text { Uno } \\
\text { Foundati } \\
\text { on } \\
\text { (MRUF) }\end{array}$ & $\begin{array}{l}13 \\
\text { Februari, } \\
2016\end{array}$ & $\begin{array}{l}\text { IY, OS, } \\
\text { AS, JM } \\
\text { dan } \\
\text { RD }\end{array}$ \\
\hline
\end{tabular}




\begin{tabular}{|c|c|c|c|c|}
\hline & $\begin{array}{l}\text { an } \\
\text { sederha } \\
\text { na usaha } \\
\text { mikro }\end{array}$ & & & \\
\hline 4 & $\begin{array}{l}\text { Fasilitas } \\
\text { pencatat } \\
\text { an } \\
\text { keuanga } \\
\text { n } \\
\text { sederha } \\
\text { na usaha } \\
\text { kuliner }\end{array}$ & $\begin{array}{l}\text { Syamsia } \\
\text { h Anwar }\end{array}$ & $\begin{array}{l}5 \text { Maret, } \\
2016\end{array}$ & HRD \\
\hline 5 & $\begin{array}{l}\text { Pelatiha } \\
\mathrm{n} \\
\text { tentang } \\
\text { konsep } \\
\text { akad } \\
\text { dari sisi } \\
\text { legal }\end{array}$ & $\begin{array}{l}\text { LPM UI } \\
\text { Fakultas } \\
\text { Ekonomi }\end{array}$ & $\begin{array}{l}10 \text { April, } \\
2016\end{array}$ & NP \\
\hline 6 & $\begin{array}{l}\text { Presenta } \\
\text { si Bank } \\
\text { Mega } \\
\text { Syariah }\end{array}$ & $\begin{array}{l}\text { Bank } \\
\text { Mega } \\
\text { Syariah }\end{array}$ & $\begin{array}{l}16 \\
\text { Februari, } \\
2016\end{array}$ & $\begin{array}{l}\text { SA dan } \\
\text { HRD }\end{array}$ \\
\hline 7 & $\begin{array}{l}\text { Rapat } \\
\text { Dinas } \\
\text { KUKM } \\
\text { Perindag } \\
\text { Bogor }\end{array}$ & $\begin{array}{l}\text { Dekopin } \\
\text { da }\end{array}$ & $\begin{array}{l}31 \text { Maret, } \\
2016\end{array}$ & HRD \\
\hline 8 & $\begin{array}{l}\text { Pembek } \\
\text { alan } \\
\text { sertifika } \\
\text { si } \\
\text { manaje } \\
\text { men }\end{array}$ & $\begin{array}{l}\text { Dekopin } \\
\text { da }\end{array}$ & $\begin{array}{l}10 \text { Mei, } \\
2016\end{array}$ & HRD \\
\hline 9 & $\begin{array}{l}\text { Sosialisa } \\
\text { si } \\
\text { Program }\end{array}$ & BPJS & $\begin{array}{l}18 \text { Mei, } \\
2016\end{array}$ & $\mathrm{NP}$ \\
\hline 10 & $\begin{array}{l}\text { Pelatiha } \\
\mathrm{n} \\
\text { pengelol } \\
\text { aan } \\
\text { ZISWAF }\end{array}$ & $\begin{array}{l}\text { Dinas } \\
\text { Koperasi }\end{array}$ & $\begin{array}{l}15-16 \\
\text { Agustus, } \\
2016\end{array}$ & HRD \\
\hline 11 & $\begin{array}{l}\text { Pelatiha } \\
\mathrm{n} \\
\text { Grafologi }\end{array}$ & $\begin{array}{l}\text { PUSKOP } \\
\text { SYAH }\end{array}$ & $\begin{array}{l}11 \\
\text { Oktober, } \\
2016 \\
\end{array}$ & HRD \\
\hline 12 & $\begin{array}{l}\text { In House } \\
\text { Training } \\
\text { (Internal } \\
\text { ) }\end{array}$ & $\begin{array}{l}\text { Manaje } \\
\text { men } \\
\text { TBU }\end{array}$ & $\begin{array}{l}\text { Tiap } \\
\text { Bulan }\end{array}$ & \\
\hline
\end{tabular}

Sumber: Data KBMT Tadbiirul Ummah, 2016

Semua kegiatan pelatihan karyawan membuktikan bahwa semua karyawan
Tadbiirul Ummah mengikuti pelatihan dengan tujuan dapat meningkatkan performance pada pengetahuan, keterampilan dan sikap/kepribadian karyawan.

\section{Kualitas SDI di Koperasi Baitul Ikhtiar (BAIK)}

Pelatihan diberikan pada semua anggota karyawan Koperasi Baitul Ikhtiar dengan tujuan untuk meningkatkan serta menambah wawasan pengurus koperasi untuk mengelola koperasi sesuai dengan praktik menjalankan usaha bisnis serta dapat menambah kemampuan pengurus atau pengelola dalam hal bekerja, meningkatkan wawasan karyawan dalam mengelola usaha koperasi dengan efektif serta efisien, meningkatkan keterampilan karyawan dibidang akuntansi koperasi dan mampu mengerjakan administrasi sesuai sistem akuntansi koperasi.

Dalam kegiatan pelatihan karyawan, Koperasi Baitul ikhtiar bekerjasama dengan instansi lain diantaranya yaitu Dinas Koperasi, BUS, BPRS, Koperasi, LAZ, NGO, Yayasan/Lembaga pendidikan, Lembaga Pelatihan dan sertifikasi.

Tabel 7

Laporan Realisasi kegiatan pelatihan SDI pada Koperasi Baitul Ikhtiar

\begin{tabular}{|l|l|l|l|l|}
\hline $\begin{array}{l}\text { N } \\
\text { o }\end{array}$ & $\begin{array}{l}\text { Nama } \\
\text { Kegiatan }\end{array}$ & Lokasi & $\begin{array}{l}\text { Pesert } \\
\text { a }\end{array}$ & $\begin{array}{l}\text { Penyele } \\
\text { nggara }\end{array}$ \\
\hline 1 & $\begin{array}{l}\text { Evaluasi } \\
\text { Bulanan }\end{array}$ & $\begin{array}{l}\text { Kantor } \\
\text { Cabang } \\
\text { Kota }\end{array}$ & $\begin{array}{l}\text { All } \\
\text { Staff } \\
\text { Caban } \\
\text { g }\end{array}$ & Cabang \\
\hline 2 & $\begin{array}{l}\text { Muhasab } \\
\text { ah }\end{array}$ & $\begin{array}{l}\text { Aula SMK } \\
\text { Nusa } \\
\text { Bangsa }\end{array}$ & $\begin{array}{l}\text { All } \\
\text { Staff } \\
\text { Caban } \\
\text { g }\end{array}$ & $\begin{array}{l}\text { KSPPS } \\
\text { BAIK }\end{array}$ \\
\hline 3 & $\begin{array}{l}\text { Parenting } \\
\text {,Pola } \\
\text { Asuh } \\
\text { Anak } \\
\text { Berbasis } \\
\text { Karakter }\end{array}$ & $\begin{array}{l}\text { Wisma } \\
\text { Gizi, } \\
\text { Semeru }\end{array}$ & $\begin{array}{l}\text { Ka. } \\
\text { Cab } \\
\text { SPV }\end{array}$ & $\begin{array}{l}\text { Indones } \\
\text { ia } \\
\text { Heritag } \\
\text { e } \\
\text { Founda } \\
\text { tion }\end{array}$ \\
\hline 4 & Pelatihan & Kantor & All & Maulan \\
\hline
\end{tabular}




\begin{tabular}{|c|c|c|c|c|}
\hline & akad & $\begin{array}{l}\text { Cabang } \\
\text { Kota }\end{array}$ & $\begin{array}{l}\text { staff } \\
\text { Caban } \\
\text { g }\end{array}$ & $\mathrm{a}$ \\
\hline 5 & R.A.T & $\begin{array}{l}\text { Gd. Surya } \\
\text { Kencana }\end{array}$ & $\begin{array}{l}\text { Ka.Cab } \\
\text { SPV }\end{array}$ & $\begin{array}{l}\text { KSPPS } \\
\text { Baik } \\
\end{array}$ \\
\hline 6 & $\begin{array}{l}\text { Qur'anic } \\
\text { Parenting }\end{array}$ & $\begin{array}{l}\text { IPB } \\
\text { Dramaga }\end{array}$ & $\begin{array}{l}\text { Ka. } \\
\text { Cab } \\
\text { SPV }\end{array}$ & $\begin{array}{l}\text { An- } \\
\text { Naba } \\
\text { Tahfidz } \\
\text { School } \\
\end{array}$ \\
\hline 7 & $\begin{array}{l}\text { TOT Pola } \\
\text { Hidup } \\
\text { Bersih\& } \\
\text { sehat }\end{array}$ & $\begin{array}{l}\text { Gd. } \\
\text { Balitbang, } \\
\text { Balitro } \\
\text { Cimanggu }\end{array}$ & $\begin{array}{l}\text { Ka. } \\
\text { Cab } \\
\text { SPV }\end{array}$ & $\begin{array}{l}\text { Team } \\
\text { Wash }\end{array}$ \\
\hline 8 & $\begin{array}{l}\text { If'thor } \\
\text { Jama'i }\end{array}$ & $\begin{array}{l}\text { Kantor } \\
\text { Cabang } \\
\text { Tamansar } \\
\text { i }\end{array}$ & $\begin{array}{l}\text { All } \\
\text { staff } \\
\text { Caban } \\
\text { g }\end{array}$ & $\begin{array}{l}\text { Kota } \\
\text { Dramag } \\
\text { a } \\
\text { Tamans } \\
\text { ari }\end{array}$ \\
\hline 9 & $\begin{array}{l}\text { I'tikaf } \\
\text { Jama'i }\end{array}$ & $\begin{array}{l}\text { Masjid } \\
\text { Daar At- } \\
\text { Taubah } \\
\text { Tamansar } \\
\text { i }\end{array}$ & $\begin{array}{l}\text { All } \\
\text { Staff } \\
\text { Caban } \\
\text { g }\end{array}$ & $\begin{array}{l}\text { KSPPS } \\
\text { Baik }\end{array}$ \\
\hline 10 & $\begin{array}{l}\text { Piloting } \\
\text { TOT } \\
\text { Sosialisas } \\
\text { i PHBS }\end{array}$ & $\begin{array}{l}\text { Kantor } \\
\text { Cabang } \\
\text { Ciampea }\end{array}$ & $\begin{array}{l}\text { Ka. } \\
\text { Cab } \\
\text { SPV }\end{array}$ & $\begin{array}{l}\text { Ka. Cab } \\
\text { KSPPS } \\
\text { BAIK }\end{array}$ \\
\hline 11 & $\begin{array}{l}\text { Pelatihan } \\
\text { akad } \\
\text { Syariah }\end{array}$ & $\begin{array}{l}\text { Gd. } \\
\text { Balitbang } \\
\text { Balitro } \\
\text { Cimanggu }\end{array}$ & $\begin{array}{l}\text { All } \\
\text { Staff } \\
\text { Caban } \\
\text { g }\end{array}$ & $\begin{array}{l}\text { BPRS } \\
\text { Amana } \\
\text { h } \\
\text { Ummah }\end{array}$ \\
\hline
\end{tabular}

Sumber: Data Koperasi Baitul Ikhtiar,2016

Pada kegiatan pelatihan dan pengembangan yang telah dilakukan, Koperasi Baitul Ikhtiar dapat memberikan motivasi kepada karyawan dalam melakukan pekerjaan serta dapat meningkatkan keterampilan kinerja dan karir karyawan. Tujuan kegiatan pelatihan pada koperasi (BAIK) yaitu untuk meningkatkan dan menambah mutu kerja Koperasi BAIK, meningkatkan kinerja dan secara otomatis dapat mencapai tujuan KSPPS BAIK. Semua kegiatan pelatihan SDI pada Koperasi membuktikan bahwa SDI ada Koperasi BAIK mengikuti semua pelatihan dengan tujuan meningkatkan performance pada pengetahuan, keterampilan dan sikap/kepribadian karyawan.

\section{KESIMPULAN DAN IMPLIKASI}

Berdasarkan uraian hasil analisis dan pembahasan yang di paparkan terkait kualitas SDI pada lima LKMS, maka disimpulkan terdapat aspek kualitas SDI diantaranya kualitas fisik yang terdiri dari sehat jasmani dan kualitas non fisik yang mencakup keterampilan, pengetahuan, sikap dan agama. Kualitas fisik (sehat jasmani) pada sebagian LKMS cukup berkualitas karena beberapa LKMS dapat menjamin kesehatan SDI nya dengan memberikan fasilitas Kartu BPJS dan setiap karyawan memiliki kartu KIS dan asuransi kesehatan. Pada kualitas non fisik (keterampilan, pengetahuan, sikap serta agama) beberapa LKMS memiliki SDI yang cukup berkualitas dan komprehensif, dalam berfikir dan mengantisipasi tuntutan masa depan serta berwawasan/berpengetahuan dan memiliki kemampuan, keterampilan, keahlian yang sesuai. Adapun beberapa SDI pada LKMS yang latar belakangnya tidak memiliki lulusan S1 ekonomi.

Kualitas SDI pada LKMS saat ini mengalami peningkatan, kemajuan yang cukup relatif dari berbagai aspek, diantaranya peningkatan kualitas diri, peningkatan kualitas pengetahuan serta peningkatan kualitas pengalaman. Kualitas kinerja karyawan di LKMS diperkuat dengan beberapa program pelatihan yang dilakukan di lingkungan pekerjaan (internal) ataupun di lingkungan pekerjaan (eksternal). Kegiatan pelatihan pada LKMS dimaksudkan untuk menambah kualitas dan kapabilitas SDI dari aspek keterampilan, pengetahuan maupun agama.

Terdapat beberapa implikasi pada penelitian ini, implikasinya yaitu: 
1. LKMS perlu melakukan perbaikan, khususnya dalam manajemen SDM, yaitu dengan diadakan evaluasi sistem

2. kualitas SDI dari aspek kualitas fisik maupun kualitas non fisik.

3. Mengenai kualitas non fisik, LKMS harus memberikan pelatihan dan pendidikan pada SDI dengan waktu setengah semester sekali dengan bertujuan meningkatkan kualitas kerja SDI pada LKMS.

\section{DAFTAR PUSTAKA}

Afif, Mohammad. 2016. Pengembangan Sumber Daya (SDI) di Lembaga Keuangan Islam. Jurnal Ekonomi Vol. 1, No 1.

Anwar, Sanusi. 2011. Metodologi Penelitian untuk Ekonomi Bisnis. Yogyakarta: UPP STIM YKPN.

Azahra, Rina Apriyani. 2015. Perbandingan Fungsi BMT Sebagai Baitul Maal Dan Baitul Tamwil. Universitas Djuanda Fakultas Ekonomi Islam. Bogor

Burhanuddin, Djaelany. 2014. Human Resources Development of Sharia Banking. Jurnal Al-Iqtishad, Vol. 20, No. 2.

Haluty, Djaelany. 2014. Islam dan Manajemen Sumber Daya Manusia yang Berkualitas. Jurnal Irfani Vol. 10, pp. 63-74. pengembangan karyawan LKMS lebih diarahkan serta mampu meningkatkan

Hidayah, Roissatun. 2015. SWOT Analysis Baitul Maal Wat Tamwil (BMT) pada Usaha Mikro. Skripsi, Yogyakarta. Universitas Islam Negri Sunan Kalijaga Yogyakarta.

Irawan, Dedik. 2013. Analisis Strategi Pengembangan Lembaga Keuangan Mikro Syariah Pedesaan (Studi Kasus BMT Al-Hasanah). Jurnal JIIA Vol 1 No 1.

Isa, Muhammad. 2014. Pengelolaan Sumber Daya Insani (SDI) Dalam Memasarkan Produk dan Jasa Lembaga Keuangan Syariah. Jurnal Kajian ilmu KeIslaman. Vol. 02 No. 2.

Istikhomah, Nurul. 2014. Analisis Kinerja Sumber Daya Insani Bank Pembiayaan Rakyat Syariah Dana Amanah Ditinjau dari Standar Kompetensi Kerja Nasional Indonesia. Jurnal UNS. Vol 2, No 2.

Jusmaliani. 2011. Pengelolaan Sumber Daya Insani (SDI), Jakarta: Bumi Aksara

Komang, Ardana I, Mujiati, Ni Wayan, dan Mudiartha Utama I Wayan. 2012. Manajemen Sumber Daya Manusia. Jakarta: Graha Ilmu.

Rivai, Veithzal. 2009. Islamic Human Capital, Dari Teori ke Praktek. PT. Raja Grafindo Persada, Jakarta 